Article

\title{
The Relationship between Epicardial Adipose Tissue Thickness and Serum Interleukin-17a Level in Patients with Isolated Metabolic Syndrome
}

\author{
Esra Demir ${ }^{1}$, Nazmiye Özlem Harmankaya ${ }^{2}$, İrem Kıraç Utku ${ }^{1}$, Gönül Açıksarı ${ }^{3}$, \\ Turgut Uygun ${ }^{4}$, Hanise Özkan ${ }^{1}$ and Bülent Demir ${ }^{5, *(1)}$ \\ 1 Department of İnternal Medicine, Kanuni Sultan Süleyman Education and Research Hospital, \\ 34103 İstanbul, Turkey; esracokicli@hotmail.com (E.D.); iremkrac@yahoo.com (İ.K.U.); \\ haniseozkan@hotmail.com (H.Ö.) \\ 2 Department of İnternal Medicine, Bakırköy Dr Sadi Konuk Education and Research Hospital, \\ 34147 İstanbul, Turkey; oharmankaya@yahoo.com \\ 3 Department of Cardiology, Medeniyet University Medical Faculty, 34722 İstanbul, Turkey; \\ drgonulkutlu@hotmail.com \\ 4 Department of Cardiology, Konya Education and Research Hospital, 42040 Konya, Turkey; \\ turgutuyguncapa@hotmail.com \\ 5 Department of Cardiology, Bakırköy Dr Sadi Konuk Education and Research Hospital, \\ 34147 İstanbul, Turkey \\ * Correspondence: drbdmr06@hotmail.com
}

Received: 6 February 2019; Accepted: 5 March 2019; Published: 11 March 2019

check for updates

\begin{abstract}
In this study, it was aimed to investigate the relationship between the epicardial adipose tissue thickness (EATT) and serum IL-17A level insulin resistance in metabolic syndrome patients. This study enrolled a total of 160 subjects, of whom 80 were consecutive patients who applied to our outpatient clinic and were diagnosed with metabolic syndrome, and the other 80 were consecutive patients who were part of the control group with similar age and demographics in whom the metabolic syndrome was excluded. The metabolic syndrome diagnosis was made according to International Diabetes Federation (IDF)-2005 criteria. EATT was measured with transthoracic echocardiography (TTE) in the subjects. IL-17A serum levels were determined using the ELISA method. Fasting blood glucose, HDL, triglyceride, and fasting insulin levels were significantly higher in the metabolic syndrome group compared to the control group. In addition, the metabolic syndrome group had significantly higher high-sensitivity C-reactive protein (hs-CRP) and Homeostatic Model Assessment Insulin Resistance (HOMA-IR) levels than the control group. Similarly, serum IL-17A levels were significantly elevated in the metabolic syndrome group compared to the control group statistically $(p<0.001)$. As well, EATT was higher in the metabolic syndrome than the control group. Conclusion: By virtue of their proinflammatory properties, EATT and IL-17 may play an important role in the pathogenesis of the metabolic syndrome.
\end{abstract}

Keywords: metabolic syndrome; adipose tissue; interleukin 17A

\section{Introduction}

Metabolic syndrome is defined as a constellation of risk factors, mainly visceral obesity accompanied by hypertension, dyslipidemia, and impaired fasting glucose. It's prevalence has been gradually increasing in parallel to an increase in the prevalence of obesity [1]. The importance of metabolic syndrome stems from an excess risk of type 2 diabetes mellitus (DM) and coronary artery disease [2]. Therefore, it has transformed into an important public health problem. Hence, it is of 
paramount importance to understand its pathogenesis and treat affected patients before it progresses to chronic disorders. Visceral obesity and associated insulin resistance play an important role for the development of metabolic syndrome. Furthermore, visceral adipose has been shown to behave differently than subcutaneous adipose and to release many cytokines and adipokines that cause the metabolic syndrome. [3]. Additionally, low-grade inflammation plays an important role for the pathogenesis of the metabolic syndrome and coronary artery disease. Hence, many studies to date have shown higher high-sensitive C-reactive protein (hs-CRP) levels, reflecting inflammation among patients with metabolic syndrome [4]. In patients with metabolic syndrome, inflammation induces insulin resistance and atherosclerosis through a variety of mechanisms [3].

Epicardial adipose tissue (EAT) is a space between the visceral pericardium and the outer margin of myocardium, whose thickness can be measured by transthoracic echocardiography (TTE). Epicardial adipose tissue (EAT) is considered an important component of chest adipose tissue, and an increasing number of studies have been conducted about it. EAT appears to play a particularly important role for the pathogenesis of coronary artery disease [5]. By virtue of its proximity to coronary arteries, EAT exerts local and parenchymal effects that effectively contribute to the development of atherosclerosis. That is, by its proximity to coronary arteries, EAT contributes to the stimulation of local inflammation that plays an important role for the initiation, progression, and complications of atherosclerosis. It has also been shown that EATT is increased in obese patients and patients with metabolic syndrome compared to the normal population [6,7]. Hence, EAT, an important component of visceral adipose tissue, appears to exacerbate inflammation and to contribute to the development of coronary artery disease and insulin resistance among patients with metabolic syndrome.

Interleukin-17 (IL-17) is a relatively novel cytokine released by helper T cells-17 (T-helper 17), which has marked proinflammatory properties. Studies have shown that the IL-17 family has several subtypes, the most important one of which appears to be IL-17A. There is scientific evidence that IL-17 plays an important role for the development of coronary artery disease and acute coronary syndromes [8,9]. Similarly, some studies have shown that IL-17 may play a role for the pathogenesis of various autoimmune disorders and DM [10,11]. A review of the literature about metabolic syndrome revealed that there is a small body of knowledge of the relationship between metabolic syndrome and IL-17. However, by virtue of its proinflammatory properties, IL-17 may play an important role for the pathogenesis of the metabolic syndrome whose pathogenesis involves inflammation.

In the light of these data, our study aimed to investigate the relationship between EAT and serum IL-17 and insulin resistance among patients with isolated metabolic syndrome, that is without coronary artery disease or DM. To our knowledge, this subject has not been yet studied in the literature.

\section{Materials and Methods}

\subsection{Study Design and Patient Selection}

Our study was designed as a prospective, observational case-control study. Our study included 80 consecutive patients ( 23 male, 57 females; mean age $39.0 \pm 11.5$ years) who presented to the endocrinology, diabetes, and obesity or internal medicine outpatient clinics and who were diagnosed with metabolic syndrome. The control group consisted of 80 patients (16 males, 64 females; mean age $39.6 \pm 9.4$ years) having similar ages and demographic characteristics but no metabolic syndrome.

The exclusion criteria included having a previous or newly diagnosed diabetes mellitus, documented coronary artery disease, acute coronary syndrome, peripheral artery disease or carotid artery stenosis, previous cerebrovascular events, myocarditis, pericarditis, cardiomyopathy, congestive heart failure, congenital heart disease, moderate-to-severe cardiac valvular disease, atrial fibrillation, active infection, autoimmune disease, active or chronic hepatitis or liver disease, impaired renal function (serum creatinine $>1.5 \mathrm{mg} / \mathrm{dL}$ or above), chronic inflammatory disease, anti-inflammatory or immune suppressive medication use. Detailed anamnesis was taken from each 
patient. Cardiovascular risk factors, namely, smoking status, hyperlipidemia, hypertension, diabetes mellitus, and family history for cardiovascular disease were questioned.

All subjects underwent detailed physical examination. Additionally, all patients were examined with twelve-lead electrocardiography. All subjects' weight and height were measured and recorded. Body mass index was calculated using the formula weight $(\mathrm{kg}) / \mathrm{height}(\mathrm{m})^{2}$. Waist circumference was measured from the narrowest horizontal distance between the lowermost rib and the anterior iliac spinal process while the patients were in upright position with their waist open.

Diabetes mellitus was defined as a fasting blood glucose level of $126 \mathrm{mg} / \mathrm{dL}$ or higher, or being on antidiabetic treatment. Patients with a plasma glucose of $100 \mathrm{mg} / \mathrm{dL}$ to $126 \mathrm{mg} / \mathrm{dL}$ were said to have impaired fasting glucose. Hypertension was defined as resting systolic blood pressure of $140 \mathrm{mmHg}$ or higher or resting diastolic blood pressure of $90 \mathrm{mmHg}$ or higher in at least three measurements, or being on antihypertensive medication.

Hyperlipidemia was defined as a total cholesterol level of $200 \mathrm{mg} / \mathrm{dL}$ or higher, or a triglyceride level of $150 \mathrm{mg} / \mathrm{dL}$ or higher [12].

Patients who were actively smoking were considered smokers irrespective of the number of cigarettes ever smoked.

Family history for coronary artery disease was defined as having a male relative with coronary artery disease younger than 55 years of age or having a female relative with coronary artery disease younger than 65 years of age.

Metabolic syndrome was diagnosed on the basis of the International Diabetes Federation 2005 Criteria [13]. It was defined as abdominal obesity, defined as a waist circumference of $>94 \mathrm{~cm}$ in men and $>80 \mathrm{~cm}$ in women, plus at least two of the criteria below:

1. High Triglyceride level: $\geq 150 \mathrm{mg} / \mathrm{dL}(1.7 \mathrm{mmol} / \mathrm{L})$.

2. Low HDL cholesterol: $<40 \mathrm{mg} / \mathrm{dL}(1.03 \mathrm{mmol} / \mathrm{L})$ in men and < 50mg/dL $(1.29 \mathrm{mmol} / \mathrm{L})$ in women.

3. High blood pressure: Systolic blood pressure $\geq 130 \mathrm{mmHg}$ or diastolic blood pressure $\geq 85 \mathrm{mmHg}$.

4. Increased fasting plasma glucose: Fasting plasma glucose $\geq 100 \mathrm{mg} / \mathrm{dL}(5.6 \mathrm{mmol} / \mathrm{L})$.

\subsection{Measurement of Epicardial Adipose Tissue Thickness by Echocardiography}

All study subjects underwent detailed two-dimensional, M-mode and Doppler echocardiographic examination by two experienced echocardiographers who were unaware of the biochemical parameters. Echocardiographic examinations were performed with a Vivid S-5 (GE Vingmed, Horten, Norway) device using a $2.5 \mathrm{MHz}-3.5 \mathrm{MHz}$ probe. Epicardial adipose tissue was defined as the adipose tissue between the pericardium and the outer margin of the myocardium [14]. In echocardiography EAT is seen as a relatively echo-free space between the outer margin of the myocardium and the visceral layer of the pericardium. In compliance with the previous reports, we measured epicardial adipose tissue thickness perpendicular to the right ventricular free wall, from the parasternal long axis and transverse views at end-diastole [14,15]. Aortic annulus and interventricular septum were used as anatomic markers to ensure perpendicularity to the right ventricular free wall [14]. In order to reduce the margin of error, final epicardial adipose thickness was calculated from the mean value of three measurements in consecutive cardiac cycles.

\subsection{Laboratory Parameters}

For biochemical analyses, blood samples were drawn from the forearm veins into dry tubes containing gel after $12 \mathrm{~h}$ of fasting. The samples were then waited for $30 \mathrm{~min}$ and centrifuged at $4000 \mathrm{rpm}$ for $10 \mathrm{~min}$. The serum sample obtained from the first tube was then transferred into an eppendorf and stored at -80 degrees for IL-17 measurement. Serum samples obtained from other tubes were studied on the same day for routine biochemistry analyses with Beckman Coulter AU5800 biochemistry autoanalyser and for hormone tests with Beckman Coulter UniCel 
DxI800 Immunoassay autoanalyser with original kits (Beckman Coulter Inc, West Sacramento, California, USA). Insulin level was measured with Siemens Immulite 2000 analyser and original kits, using and the chemiluminescence method (Siemens Healthcare, Erlangen, Germany). Complete blood count analysis was performed from the blood samples taken into ethylenediaminetetraacetic acid (EDTA) containing tubes, using a Beckman Coulter LH 750 analyser.

\subsection{Determination of Serum IL-17A Level}

After completing collection of all blood samples, stored at $-80^{\circ} \mathrm{C}$. Serum samples were thawed to room temperature for Il-17 analysis. IL-17 level was quantitatively determined with Diaclone Human IL-17A ELISA Kit (catalog 850.940.096, Lot 117A-12), using ELISA (Enzyme -Linked Immunosorbent Assay) method based on the sandwich method, in compliance with the procedure recommended by the manufacturer. The results of were reported as $\mathrm{pg} / \mathrm{ml}$. The intraassay and intraassay coefficients of variation, reflecting the measurement's specific performance properties, were determined as $3.3 \%$ and $5.2 \%$, respectively.

\subsection{Other Parameters}

Serum hs-CRP level was measured nephelometrically, using a BN-II nephelometer (Siemens Healthcare Diagnostics, Los Angeles, CA, USA). Insulin resistance was calculated using the homeostasis model assessment insulin resistance index (HOMA-IR) formula [16].

This study was conducted in compliance with the Helsinki Declaration and approved by the ethics committee of our hospital (Decision Number: 2013/09/01). All subjects gave written informed consent before study entry.

\subsection{Statistical Analysis}

Study data were analysed using Windows (SPSS Inc, Chicago, IL, USA) SPSS software package, version 22.0. Descriptive statistics included frequency, ratio, mean, median, minimum, maximum, and standard deviation. Normality of distribution was tested with Kolmogorov-Smirnov test. Quantitative data were analyzed using independent samples $\mathrm{T}$ test and Mann-Whitney $U$ test. Qualitative data were analyzed using Chi-Square test. Correlation analyses were performed with Spearman correlation analysis. Multivariable linear regression analysis was performed to determine the level of effect. Standard beta coefficients and 95\% confidence intervals were calculated. Receiver operator characteristics (ROC) curve analysis was done to calculate cut off levels for differentiating patients with metabolic syndrome. Statistical significance was set at $p<0.05$.

\section{Results}

Patient's demographic data, clinical properties, and laboratory parameters were summarized on Table 1. There was no significant difference between the metabolic syndrome and control groups with respect to age, sex, and rate of smoking $(p>0.05)$. The metabolic syndrome group had significantly higher rates of hypertension, hyperlipidemia, and family history for coronary artery disease, as well as numerical value BMI, systolic blood pressure, and diastolic blood pressure $(p<0.001)$.

The comparison of the laboratory's parameters and echocardiographic parameters revealed that fasting plasma glucose, HDL, Triglyceride, GGT, AST, ALT and fasting insulin levels were significantly greater in the metabolic syndrome group (for all comparisons, $p<0.01$ ). As for insulin resistance, the comparison of HOMA-IR values between the two groups showed that the metabolic syndrome group had a significantly greater HOMA-IR level compared to the control group (5.2 \pm 2.3 vs. $1.4 \pm$ $0.6, p<0.001$ ) (Table 1).

Similarly, serum hs-CRP level was significantly greater in the metabolic syndrome group compared to the control group $(3.8 \pm 0.6 \mathrm{mg} / \mathrm{L}$ vs. $0.8 \pm 0.8 \mathrm{mg} / \mathrm{L}, p<0.001)$ (Table 1 ).

Epicardial adipose tissue thickness was significantly greater in patients with metabolic syndrome than the controls $(6.2 \pm 2.2 \mathrm{~mm}$ vs. $4.0 \pm 0.8 \mathrm{~mm}, p<0.001)$ (Table 1) (Figure 1). 
Table 1. Comparison of the demographic and clinical properties and laboratory results between the metabolic syndrome and control groups.

\begin{tabular}{|c|c|c|c|}
\hline \multirow{2}{*}{ Parameter } & Metabolic Syndrome Group & Control Group & \multirow{2}{*}{$p$ Value } \\
\hline & Mean \pm Standard Deviation & Mean \pm Standard Deviation & \\
\hline Age, years & $39.0 \pm 11.5$ & $39.6 \pm 9.4$ & 0.747 \\
\hline Sex (Male/Female) & $23 / 57$ & $16 / 64$ & 0.197 \\
\hline BMI, $\mathrm{kg} / \mathrm{m}^{2}$ & $34.8 \pm 6.7$ & $25.9 \pm 4.9$ & $<0.001$ \\
\hline Smoking, $n$ & 30 & 24 & 0.316 \\
\hline Hypertension, $n$ & 50 & 4 & $<0.001$ \\
\hline Hyperlipidemia, $n$ & 11 & 4 & 0.058 \\
\hline Family history, $n$ & 50 & 25 & $<0.001$ \\
\hline Systolic blood presure, $\mathrm{mmHg}$ & $133.8 \pm 22.4$ & $111.3 \pm 13.4$ & $<0.001$ \\
\hline Diastolic blood pressure, $\mathrm{mmHg}$ & $83.8 \pm 12.4$ & $71.3 \pm 9.6$ & $<0.001$ \\
\hline Glucose, $\mathrm{mg} / \mathrm{dL}$ & $96.4 \pm 11.7$ & $84.9 \pm 10.3$ & $<0.001$ \\
\hline Urea, mg/dL & $26.8 \pm 10.4$ & $25.1 \pm 6.8$ & 0.246 \\
\hline Creatinine, $\mathrm{mg} / \mathrm{dL}$ & $0.7 \pm 0.2$ & $0.7 \pm 0.4$ & 0.536 \\
\hline T. Chol, mg/dL & $189.7 \pm 38.6$ & $183.1 \pm 39.5$ & 0.077 \\
\hline $\mathrm{LDL}, \mathrm{mg} / \mathrm{dL}$ & $110.4 \pm 29.8$ & $106.3 \pm 33.9$ & 0.102 \\
\hline $\mathrm{HDL}, \mathrm{mg} / \mathrm{dL}$ & $44.7 \pm 11.2$ & $51.9 \pm 11.9$ & $<0.001$ \\
\hline $\mathrm{TG}, \mathrm{mg} / \mathrm{dL}$ & $183.3 \pm 91.0$ & $108.7 \pm 67.6$ & $<0.001$ \\
\hline GGT, U/L & $28.9 \pm 19.3$ & $20.5 \pm 17.0$ & $<0.001$ \\
\hline AST, U/L & $27.5 \pm 17.1$ & 23.8. \pm 18.7 & 0.007 \\
\hline ALT, U/L & $33.0 \pm 28.1$ & $23.8 \pm 33.5$ & $<0.001$ \\
\hline Insulin, $\mathrm{mIU} / \mathrm{mL}$ & $22.0 \pm 9.6$ & $18.5 \pm 10.3$ & $<0.001$ \\
\hline HOMA-IR & $5.2 \pm 2.3$ & $1.4 \pm 0.6$ & $<0.001$ \\
\hline IL-17A, pg /mL & $2.9 \pm 3.7$ & $0.1 \pm 0.2$ & $<0.001$ \\
\hline hs-CRP, mg/L & $3.8 \pm 0.6$ & $0.8 \pm 0.8$ & $<0.001$ \\
\hline EATT, mm & $6.2 \pm 2.2$ & $4.0 \pm 0.8$ & $<0.001$ \\
\hline $\mathrm{Hb}, \mathrm{g} / \mathrm{dL}$ & $13.1 \pm 1.8$ & $12.7 \pm 1.6$ & 0.169 \\
\hline Thrombocyte count $\left(\times 10^{9}\right)$ & $286.9 \pm 110.9$ & $257.1 \pm 64.1$ & 0.069 \\
\hline
\end{tabular}

BMI, body mass index, T.Chol, Total cholesterol, LDL: ow density lipoprotein, HDL, high density lipoprotein, TG, triglyceride, GGT, Gamma-glutamyl transferase; AST, aspratate aminotransferase; ALT, alanine aminotransferase; HOMA-IR, homeostatic model assessment-insulin resistance; IL-17A; Interleukin 17A; hsCRP, high sensitive C-reactive protein; EATT, epicardial adipose tissue thickness.

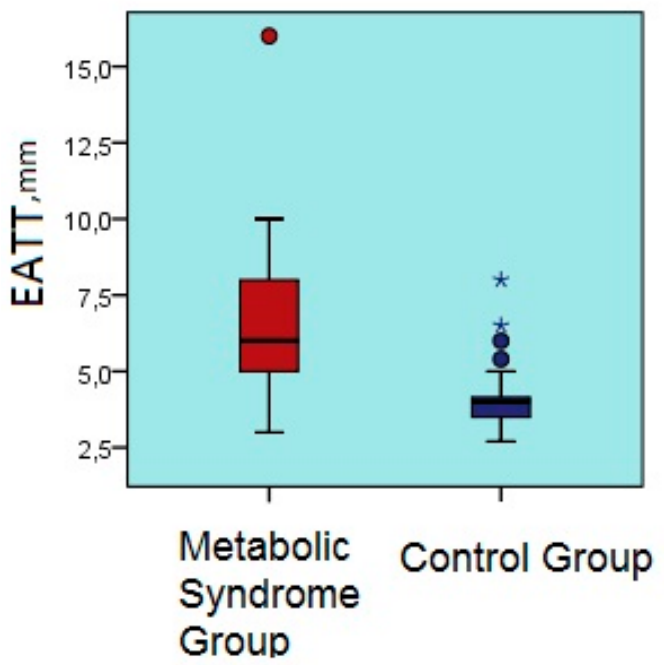

Figure 1. Comparison of epicardial adipose tissue thicknesses of the metabolic syndrome and control groups. EATT, epicardial adipose tissue thickness.

Serum interleukin 17A level was significantly greater in the metabolic syndrome group compared to the control group $(2.9 \pm 3.7 \mathrm{pg} / \mathrm{mL}$ vs. $0.1 \pm 0.2 \mathrm{pg} / \mathrm{mL}, p<0.001)$ (Table 1) (Figure 2). 


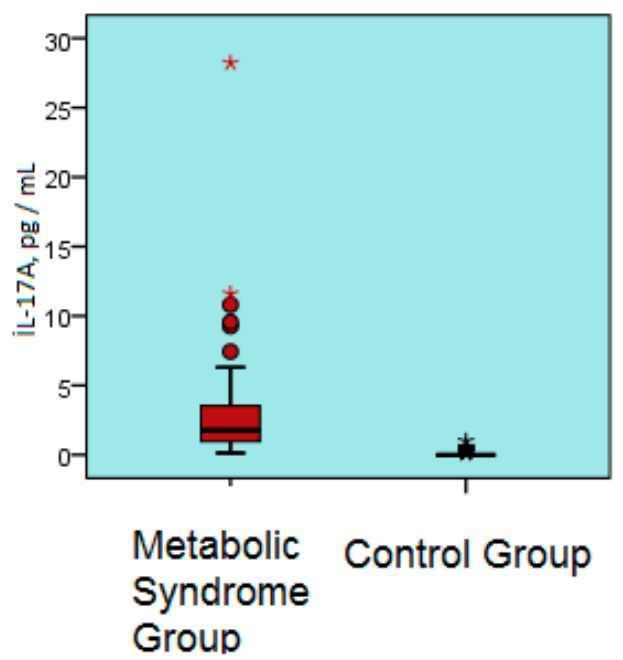

Figure 2. Serum IL-17A levels of the metabolic syndrome and control groups. IL-17A; interleukin $17 \mathrm{~A}, \mathrm{pg} / \mathrm{mL}$.

There was a positive correlation between EATT and age, BMI, glucose level, insulin, Tg, GGT, HOMA-IR, hs-CRP, IL-17A, urea, systolic blood pressure, and diastolic blood pressure $(\mathrm{r}=0.180$, $\mathrm{r}=0.539, \mathrm{r}=0.194, \mathrm{r}=0.279, \mathrm{r}=0.556, \mathrm{r}=0.281, \mathrm{r}=0.666, \mathrm{r}=0.308, \mathrm{r}=0.181, \mathrm{r}=0.421$, and $\mathrm{r}=0.394$, respectively; for all comparisons, $p<0.05$ ) (Table 2) (Figures 3 and 4 ).

Table 2. Correlation analysis between EATT and the other parameters.

\begin{tabular}{|c|c|c|c|c|c|c|c|c|c|c|c|c|c|c|c|}
\hline Parame & & Age & BMI & Glucose & İnsulin & LDL & TG & HDL & GGT & HOMA-IR & hs-CRP & İL-17A & Urea & SBP & DBP \\
\hline \multirow{2}{*}{ EATT } & $\mathrm{r}$ & 0.180 & 0.539 & 0.194 & 0.556 & 0.092 & 0.279 & -0.142 & 0.281 & 0.567 & 0.666 & 0.308 & 0.181 & 0.421 & 0.394 \\
\hline & $p$ & 0.023 & 0.000 & 0.014 & 0.000 & 0.248 & 0.000 & 0.074 & 0.000 & 0.000 & 0.000 & 0.000 & 0.022 & 0.000 & 0.000 \\
\hline
\end{tabular}

EATT, epicardial adipose tissue thickness; BMI, body mass index; LDL, low density lipoprotein; TG, triglyceride; HDL, high density lipoprotein GGT, Gamma-glutamyl transferase; HOMA-IR, homeostatic model assessment-insulin resistance; hs-CRP, high sensitive C-reactive protein; IL-17A; Interleukin 17A; SBP, systolic blood pressure; DBP, diastolic blood pressure.

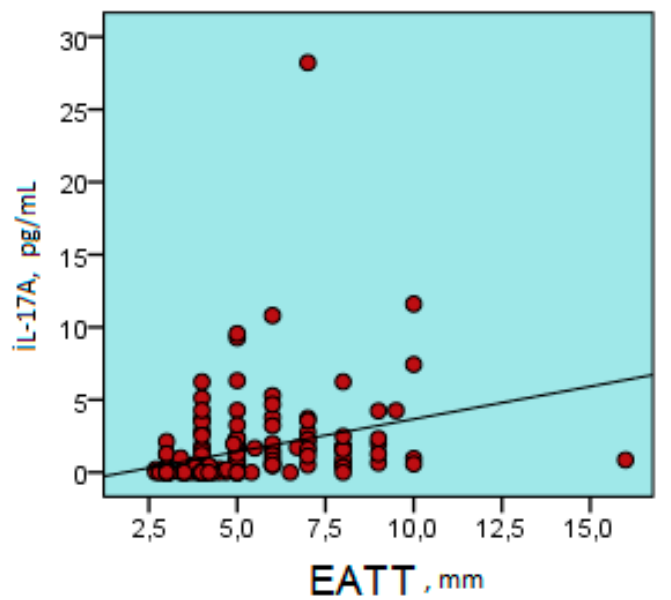

Figure 3. Positive correlation between epicardial adipose tissue thickness and serum IL-17A level $(\mathrm{r}=0.308, p<0.001)$. IL-17A; interleukin 17A, pg/ mL; EATT, Epicardial Adipose Tissue Thickness. 


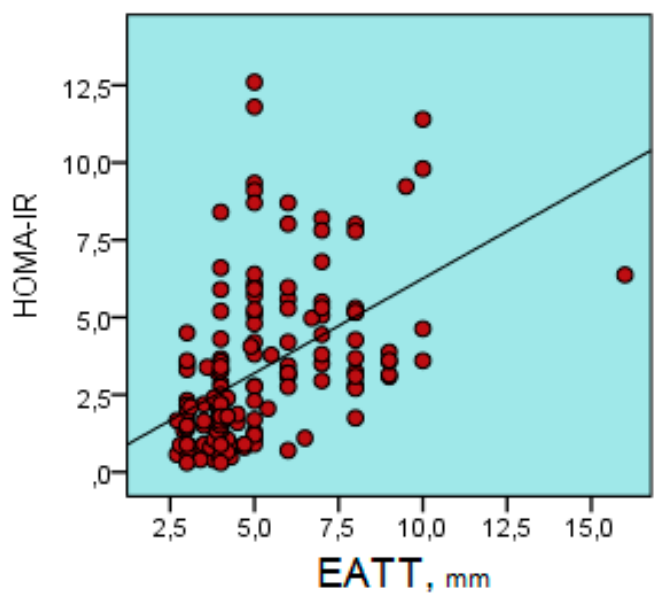

Figure 4. Positive correlation between epicardial adipose tissue thickness and HOMA-IR $(\mathrm{r}=0.567$, $p<0.001$ ). HOMA-IR, Homeostasis Model Assessment İnsulin Resistance Index; EATT, Epicardial Adipose Tissue Thickness.

A multivariable linear regression analysis showed that EATT was significantly correlated to age, diastolic blood pressure, HOMA-IR and urea (for all comparisons, $p<0.05$ ) (Table 3).

Table 3. Multivariable Linear Regression Analysis to determine the Effects of Independent Variables on EATT.

\begin{tabular}{cccccc}
\hline Multivariable Model & B & Standard Error & Beta & $\mathbf{t}$ & $\boldsymbol{p}$ \\
\hline Age & 0.00 & 0.00 & 0.18 & 2.70 & 0.008 \\
Diastolic blood pressure & 0.00 & 0.00 & 0.22 & 3.06 & 0.003 \\
HOMA-IR & 0.03 & 0.01 & 0.40 & 5.65 & 0.000 \\
urea & 0.00 & 0.00 & 0.17 & 2.58 & 0.011 \\
\hline
\end{tabular}

The Predictive Values of Epicardial Adipose Tissue Thickness and Interleukin 17A Level for Metabolic Syndrome

The receiver operator characteristics (ROC) curve analysis showed that values above a cutoff level of $4.7 \mathrm{~mm}$ for EATT had a sensitivity of $77.5 \%$, a specificity of $87.5 \%$, a positive predictive value of $86.1 \%$, and a negative predictive value of $79.5 \%$ for metabolic syndrome (area under the curve; 0.83 , 95\% Confidence Interval: 0.76-0.89, $p<0.001$ ) (Figure 5).

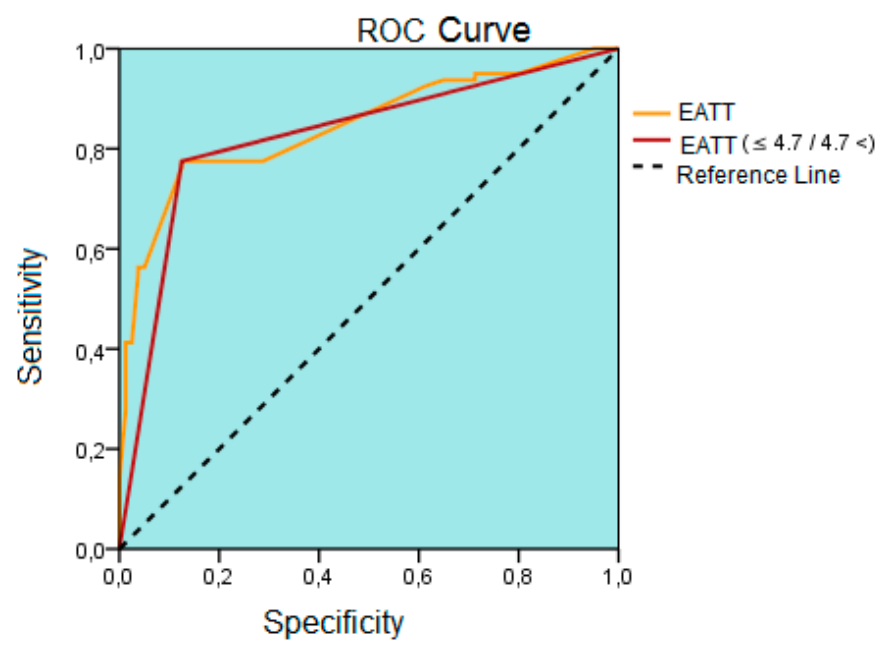

Figure 5. The result of the receiver operating characteristics (ROC) curve analysis drawn to determine the best cutoff point of epicardial adipose tissue thickness to differentiate patients with metabolic syndrome. ROC; receiver operating characteristics, EATT; epicardial adipose tissue thickness, mm; millimeter. 


\section{Discussion}

The main finding of our study was that the EATT and IL-17A level were higher among patients with metabolic syndrome compared to the control group. The other important finding of our study was that there was a positive correlation between serum IL-17 A level and EATT and insulin resistance. According to our knowledge, our study is the first to scrutinize the relationship between IL-17A, EAT, and insulin resistance.

Metabolic syndrome is a cluster of risk factors, the prevalence of which has been gradually increasing. Visceral obesity is of particular importance to the development of the metabolic syndrome. As is well known, EAT is an important component of adipose tissue. We detected a greater EATT among patients with metabolic syndrome than the control group, which is evidence of increased chest adipose accumulation. This finding was further supported by a positive correlation between BMI and EATT. In parallel to our findings, a sufficient number of studies have shown that EATT increased among patients with metabolic syndrome [17-20]. Increased EAT may contribute to increased incidence of coronary artery disease in this population because visceral adipose tissue is a metabolically active and may contribute to atherosclerosis by synthesizing many adipocytokines. Furthermore, the close proximity of EAT to coronary arteries suggests that it may contribute to the appearance of atherosclerosis not only by its systemic actions, but also by local and paracrine effects. Low-grade inflammation is particularly effective for the development of atherosclerosis. As EAT is a component of chest adipose tissue, it is expected to play a role for the inflammatory changes. Hence, Mazurek et al. showed that human epicardial adipose tissue is an important source of inflammatory mediators [21]. In that study, they showed that IL-1, IL-6, IL-6sR, and TNF-alpha expression was greater in epicardial adipose tissue than that in subcutaneous adipose tissue among patients with coronary artery disease [21]. Interestingly, that same study failed to detect any increase in the serum levels of the cytokines with increased EAT expression [21]. In the light of all the above mentioned data, it becomes clear that EAT has local proinflammatory effects. In another study by Iacobellis et al. where biopsy samples taken from epicardial adipose tissue among patients undergoing elective cardiac surgery, a significantly reduced adiponectin level was detected by the Western Blot method among patients with coronary artery disease [22]. Adiponectin is an important adipokine known to have anti-inflammatory and antiatherosclerotic properties. Detection of a lower adiponectin level in epicardial adipose tissue in patients with coronary artery disease suggests that epicardial adipose tissue impairs anti-inflammatory/proinflammatory balance in favor of proinflammation, contributing to atherosclerosis by inducing local inflammation. Similarly, Hirata et al., in a study on EAT biopsy samples obtained from patients undergoing elective cardiac surgery, demonstrated that macrophage polarization shifted towards proinflammation in epicardial adipose tissue in patients with coronary artery disease [23]. They reach that conclusion by demonstrating a higher M1/M2 ratio, reflecting proinflammatory and anti-inflammatory state in macrophages, among patients with coronary artery disease than those without [23]. Furthermore, they also found a positive correlation between the expression of proinflammatory cytokines and M1/M2 ratio in EAT but found a negative correlation between the expression of anti-inflammatory cytokines and the M1/M2 ratio [23]. This supports the notion that EAT induces marked inflammation and thus plays an active role for the development of atherosclerosis. Another interesting finding of the present study was the absence of any significant difference between patients with and without coronary artery disease with respect to macrophage infiltration and cytokine expression in subcutaneous adipose tissue [23]. This supports the view that EAT is an important component of chest adipose tissue and paves the way for inflammation, which actively plays a role in the pathogenesis of many cardiometabolic disorders.

As is known, one of the major diagnostic criteria of metabolic syndrome is increased waist circumference reflecting visceral obesity. Increased EATT among patients with metabolic syndrome is a reflection of visceral obesity. Hence, clinical studies among obese persons found a significant positive correlation between EAT and obesity [24,25]. Willens et al. showed a significant reduction in EATT in parallel to total weight loss among patients undergoing bariatric surgery [26]. All those data suggest 
that EAT is an important component of visceral obesity. We found a positive correlation between EATT and BMI, further supporting this hypothesis.

One of the main problems with metabolic syndrome is insulin resistance and its clinical consequences, that is impaired fasting glucose and type 2 DM. Therefore, as a component of visceral obesity, EAT may play a role for the development of insulin resistance. Iacobellis et al., in a study on non-diabetics, found a significant positive correlation between EATT and impaired fasting glucose [27]. The same research also showed a significant correlation between EATT and fasting glucose [28]. A recent study on postmenopausal women showed a correlation between EAT and visceral adipose tissue, metabolic syndrome, and insulin resistance [29].

Another important finding of our study is that the IL-17A level was significantly greater among patients with metabolic syndrome compared to the control subjects. Interleukin 17A is a relatively novel cytokine that is released by lymphocytes called T-17 and known to have proinflammatory effects. There is limited information in the literature as to the relationship between metabolic syndrome and IL-17. The most important of these data comes from the study by Surendar et al. on patients with metabolic syndrome [30]. That study reported a lower serum IL-17A level among patients with metabolic syndrome compared to the controls [30]. That same study found that the serum transforming growth factor (TGF) $\beta$ level was higher among patients with metabolic syndrome than the control subjects [30]. This is an unexpected finding with respect to IL-17A, which has proinflammatory properties. This paradoxical result can be explained by that study's cross-sectional design and a relatively lower number of subjects. Unlike that study, we detected higher IL-17A level among patients with isolated metabolic syndrome. Thanks to its marked proinflammatory properties, IL-17A may play an important role for the pathogenesis of the metabolic syndrome. This was evidenced by Ohshima et al. who found that IL-17 induced insulin resistance through type 1 receptors of angiotensin 2 in mice [31]. This is because IL-17 also induces the production of IL-6 and TNF-alpha, the cytokines with marked proinflammatory effects that play an important role for the development of insulin resistance [31]. Another study showed that IL-17 play a role for adipocyte differentiation and glucose hemostasis [32]. In that study glucose tolerance and insulin sensitivity was increased among young mice with experimentally created IL-17 deficiency [32]. Hence, IL-17 appears to play a role for glucose metabolism and insulin resistance. Our finding that the patients with metabolic syndrome had a higher IL-17A level also corroborates this notion. Another finding of our study is a significant positive correlation between EAT and IL-17A. As is known, adipocytes may synthesize many cytokines. Additionally, IL-17 has also been shown to play a role for adipocyte differentiation [32]. That is, EAT may exert some of its proinflammatory properties through IL-17. However, this view is only a hypothesis for now because there is no literature information related to the association of EAT and IL-17A. There is a need to conduct experimental and clinical research in this field, including the demonstration of IL-17 expression in EAT. On the other hand, there is strong evidence that IL-17A plays a role in the pathogenesis of atherosclerosis [33,34]. IL-17 expression has been shown in human atheroma plaques [33]. Moreover, it has been reported that some of the IL-17 family are expressed in inflammatory cells infiltrating vascular wall, suggesting that IL-17 family may play a role for the development, progression and complications of atherosclerosis [34]. The most important complication of atherosclerosis is rupture of vulnerable plaques and associated acute coronary syndrome. In this regard, Hashmi et al. reported that serum IL-17A level was increased among patients with acute coronary syndrome [35]. Based on this information, IL-17A may play a role for the conversion of stable coronary plaques into vulnerable plaques with a tendency to rupture. Alteration of macrophage polarization in favour of inflammation also facilitates the conversion of coronary atheroma plaques to vulnerable plaques. That is because macrophages play an important role by synthesizing many proinflammatory cytokines and producing mediators such as matrix metalloproteinases. These data obtained from recent studies suggest that IL-17 plays a role in many stages of atherosclerosis [36-38]. We detected an increased serum IL-17A and a positive correlation between serum IL-17A level and EAT, which may be interpreted as an indirect sign of increased coronary artery disease risk among a 
metabolic syndrome population. Another finding of our study is that an EATT value of $4.7 \mathrm{~mm}$ was the cut-off point for prediction of metabolic syndrome. However, the specificity and sensitivity of this cutoff value were relatively low. Bertaso et al. reported that, based on the available data, EATT values above 5 should be considered abnormal [14]. We found a somewhat lower value (4.7 $\mathrm{mm})$. An additional point to consider in this sense is that ethnic origin and racial differences may alter EATT. In conclusion, our cutoff value only applies for the Turkish population. On the other hand, since EAT measurement by echocardiography, which is a simple, inexpensive, and noninvasive method, and an EAT level above this cutoff level would suggest metabolic syndrome among asymptotic individuals, a public health benefit may be obtained by echocardiographic examination of EATT.

Our study has some limitations. A small sample size is it's main limitation. However, the main reason of this is the exclusion of diabetic and coronary artery disease patients. That is, our study included patients with metabolic syndrome alone. Another important limitation of our study is the measurement of epicardial adipose tissue by echocardiography alone, despite the latter appearing correlated to other imaging methods such as MRI and CT. Moreover, determination of serum Il-17A level by a single measurement and lacking serial measurements and long-term follow-up are the other limitations. On the other hand, we measured Il-17A level from the serum, that is we performed a systemical measurement. Hence, this measurement does not reflect IL-17A's local and paracrine effects. Additionally; the high IL-17A serum level could reflect as a result of the cumulative effect of other metabolic tissue, such as; visceral adipose tissue and liver. Furthermore, the lack of an assessment of signs of subclinical atherosclerosis such as carotis intima media thickness or coronary calcium score among patients with metabolic syndrome may be considered another limitation. Finally, the lack of measure of other additional proinflammatory cytokines and adipokines could be considered as an important limitation of our study.

In conclusion, epicardial adipose tissue and IL-17A may be associated with the development of insulin resistance, coronary atherosclerosis, and type $2 \mathrm{DM}$ due to their proinflammatory properties among patients with metabolic syndrome. More comprehensive studies are needed to determine the relationship between epicardial adipose tissue and IL-17A more precisely among patients with metabolic syndrome.

Author Contributions: For research articles with several authors, a short paragraph specifying their individual contributions must be provided. The following statements should be used "Conceptualization, E.D. and B.D.; Methodology, E.D.; Software, H.Ö.; Validation, G.A., T.U. and İ.K.U.; Formal Analysis, N.Ö.H.; Investigation, H.Ö.; Resources, B.D.; Data Curation, G.A.; Writing-Original Draft Preparation, E.D.; Writing-Review \& Editing, B.D.; Visualization, T.U.; Supervision, I.K.U.; Project Administration, N.Ö.H.; Funding Acquisition, E.D.

Funding: This research received no external funding.

Conflicts of Interest: The authors declare no conflict of interest.

\section{References}

1. El Brini, O.; Akhouayri, O.; Gamal, A.; Mesfioui, A.; Benazzouz, B. Prevalence of metabolic syndrome and its components based on a harmonious definition among adults in Morocco. Diabetes Metab. Syndr. Obes. 2014, 7, 341-346. [CrossRef] [PubMed]

2. Shin, J.A.; Lee, J.H.; Lim, S.Y.; Ha, H.S.; Kwon, H.S.; Park, Y.M.; Lee, W.C.; Kang, M.I.; Yim, H.W.; Yoon, K.H.; et al. Metabolic syndrome as a predictor of type 2 diabetes, and its clinical interpretations and usefulness. J. Diabetes Investig. 2013, 4, 334-343. [CrossRef] [PubMed]

3. Kaur, J. A comprehensive review on metabolic syndrome. Cardiol. Res. Pract. 2014, 2014, 943162. [CrossRef] [PubMed]

4. Voils, S.A.; Cooper-DeHoff, R.M. Association between high sensitivity C-reactive protein and metabolic syndrome in subjects completing the National Health and Nutrition Examination Survey (NHANES) 2009-2010. Diabetes Metab. Syndr. 2014, 8, 88-90. [CrossRef] [PubMed] 
5. Wu, F.Z.; Chou, K.J.; Huang, Y.L.; Wu, M.T. The relation of location-specific epicardial adipose tissue thickness and obstructive coronary artery disease: Systemic review and meta-analysis of observational studies. BMC Cardiovasc. Disord. 2014, 14, 62. [CrossRef] [PubMed]

6. Balcioğlu, A.S.; Durakoğlugil, M.E.; Ciçek, D.; Bal, U.A.; Boyaci, B.; Müderrisoğlu, H. Epicardial adipose tissue thickness and plasma homocysteine in patients with metabolic syndrome and normal coronary arteries. Diabetol. Metab. Syndr. 2014, 6, 62. [CrossRef] [PubMed]

7. Tok, D.; Kadife, I.; Turak, O.; Ozcan, F.; Başar, N.; Cağlı, K.; Aras, D.; Topaloğlu, S.; Aydoğdu, S. Increased epicardial adipose thickness is associated with low grade systemic inflammation in metabolic syndrome. Turk Kardiyol. Dern. Ars. 2012, 40, 690-695. [CrossRef] [PubMed]

8. Wang, Z.; Lee, J.; Zhang, Y.; Wang, H.; Liu, X.; Shang, F.; Zheng, Q. Increased Th17 cells in coronary artery disease are associated with neutrophilic inflammation. Scand. Cardiovasc. J. 2011, 45, 54-61. [CrossRef] [PubMed]

9. Zhu, F.; Wang, Q.; Guo, C.; Wang, X.; Cao, X.; Shi, Y.; Gao, F.; Ma, C.; Zhang, L. IL-17 induces apoptosis of vascular endothelial cells: A potential mechanism for human acute coronary syndrome. Clin. Immunol. 2011, 141, 152-160. [CrossRef] [PubMed]

10. Benedetti, G.; Miossec, P. Interleukin 17 contributes to the chronicity of inflammatory diseases such as rheumatoid arthritis. Eur. J. Immunol. 2014, 44, 339-347. [CrossRef] [PubMed]

11. Li, C.R.; Mueller, E.E.; Bradley, L.M. Islet antigen-specific Th17 cells can induce TNF- $\alpha$-dependent autoimmune diabetes. J. Immunol. 2014, 192, 1425-1432. [CrossRef] [PubMed]

12. Cleeman, J.I.; Grundy, S.M.; Becker, D.; Clark, L. Expert Panel on Detection, Evaluation and Treatment of High Blood Cholesterol in Adults; Executive Summary of the Third Report of the National Cholesterol Education Program (NCEP) Expert Panel on Detection, Evaluation, and Treatment of High Blood Cholesterol in Adults (Adult Treatment Panel III). JAMA 2001, 285, 2486-2497.

13. International Diabetes Fedaration. The IDF Consensus Worldwide Defination of the Metabolic Syndrome. 2005. Available online: http:/www.idf.org/webdata/docs/metac_syndrome_def.pdf (accessed on 24 September 2005).

14. Bertaso, A.G.; Bertol, D.; Duncan, B.B.; Foppa, M. Epicardial adipose: Definition, measurements and systematic review of main outcomes. Arq. Bras. Cardiol. 2013, 101, e18-e28. [CrossRef] [PubMed]

15. Park, J.S.; Ahn, S.G.; Hwang, J.W.; Lim, H.S.; Choi, B.J.; Choi, S.Y.; Yoon, M.H.; Hwang, G.S.; Tahk, S.J.; Shin, J.H. Impact of body mass index on the relationship of epicardial adipose tissue to metabolic syndrome and coronaryartery disease in an Asian population. Cardiovasc. Diabetol. 2010, 9, 29. [CrossRef] [PubMed]

16. Matthews, D.R.; Hosker, J.P.; Rudenski, A.S.; Naylor, B.A.; Treacher, D.F.; Turner, R.C. Homeostasis model assessment: Insulin resistance and beta-cell function from fasting plasma glucose and insulin concentrations in man. Diabetologia 1985, 28, 412-419. [CrossRef] [PubMed]

17. Lima-Martínez, M.M.; Paoli, M.; Donis, J.H.; Odreman, R.; Torres, C.; Iacobellis, G. Cut-off point of epicardial adipose tissue thickness for predicting metabolic syndrome in Venezuelan population. Endocrinol. Nutr. 2013, 60, 570-576. [CrossRef] [PubMed]

18. Wang, C.P.; Hsu, H.L.; Hung, W.C.; Yu, T.H.; Chen, Y.H.; Chiu, C.A.; Lu, L.F.; Chung, F.M.; Shin, S.J.; Lee, Y.J. Increased epicardial adipose tissue (EAT) volume in type 2 diabetes mellitus and association with metabolic syndrome and severity of coronary atherosclerosis. Clin. Endocrinol. 2009, 70, 876-882. [CrossRef] [PubMed]

19. Iacobellis, G.; Ribaudo, M.C.; Assael, F.; Vecci, E.; Tiberti, C.; Zappaterreno, A.; Di Mario, U.; Leonetti, F. Echocardiographic epicardial adipose tissue is related to anthropometric and clinical parameters of metabolic syndrome: A new indicator of cardiovascular risk. J. Clin. Endocrinol. Metab. 2003, 88, 5163-5168. [CrossRef] [PubMed]

20. Yorgun, H.; Canpolat, U.; Hazırolan, T.; Ateş, A.H.; Sunman, H.; Dural, M.; Şahiner, L.; Kaya, E.B.; Aytemir, K.; Tokgözoğlu, L.; et al. Increased epicardial adipose tissue is a marker of metabolic syndrome in adult patients. Int. J. Cardiol. 2013, 165, 308-313. [CrossRef] [PubMed]

21. Mazurek, T.; Zhang, L.; Zalewski, A.; Mannion, J.D.; Diehl, J.T.; Arafat, H.; Sarov-Blat, L.; O’brien, S.; Keiper, E.A.; Johnson, A.G.; et al. Human epicardial adipose tissue is a source of inflammatory mediators. Circulation 2003, 108, 2460-2466. [CrossRef] [PubMed]

22. Iacobellis, G.; Pistilli, D.; Gucciardo, M.; Leonetti, F.; Miraldi, F.; Brancaccio, G.; Gallo, P.; Di Gioia, C.R. Adiponectin expression in human epicardial adipose tissue in vivo is lower in patients with coronary artery disease. Cytokine 2005, 29, 251-255. [CrossRef] [PubMed] 
23. Hirata, Y.; Tabata, M.; Kurobe, H.; Motoki, T.; Akaike, M.; Nishio, C.; Higashida, M.; Mikasa, H.; Nakaya, Y.; Takanashi, S.; et al. Coronary atherosclerosis is associated with macrophage polarization in epicardial adipose tissue. J. Am. Coll. Cardiol. 2011, 58, 248-255. [CrossRef] [PubMed]

24. Gorter, P.M.; van Lindert, A.S.; de Vos, A.M.; Meijs, M.F.; van der Graaf, Y.; Doevendans, P.A.; Prokop, M.; Visseren, F.L. Quantification of epicardial and peri-coronary adipose using cardiac computed tomography; reproducibility and relation with obesity and metabolic syndrome in patients suspected of coronary artery disease. Atherosclerosis 2008, 197, 896-903. [CrossRef] [PubMed]

25. Iacobellis, G.; Willens, H.J.; Barbaro, G.; Sharma, A.M. Threshold values of high-risk echocardiographic epicardial adipose thickness. Obesity 2008, 16, 887-892. [CrossRef] [PubMed]

26. Willens, H.J.; Byers, P.; Chirinos, J.A.; Labrador, E.; Hare, J.M.; de Marchena, E. Effects of weight loss after bariatric surgery on epicardial adipose measured using echocardiography. Am. J. Cardiol. 2007, 99, 1242-1245. [CrossRef] [PubMed]

27. Iacobellis, G.; Barbaro, G.; Gerstein, H.C. Relationship of epicardial adipose thickness and fasting glucose. Int. J. Cardiol. 2008, 128, 424-426. [CrossRef] [PubMed]

28. Pierdomenico, S.D.; Pierdomenico, A.M.; Cuccurullo, F.; Iacobellis, G. Meta-analysis of the relation of echocardiographic epicardial adipose tissue thickness and the metabolic syndrome. Am. J. Cardiol. 2013, 111, 73-78. [CrossRef] [PubMed]

29. Muñoz, M.J.; Acevedo, L.B.; Pérez, N.C.; Martínez, A.L.; Gutiérrez, N.T.; García, S.V.; Cruz, A.R.; Martínez, A.D.; García, R.S.; Treviño, A.Z.; et al. Epicardial adipose tissue is associated with visceral adipose, metabolic syndrome, and insulin resistance in menopausal women. Revista Española Cardiología 2014, 67, 436-441. [CrossRef]

30. Surendar, J.; Aravindhan, V.; Rao, M.M.; Ganesan, A.; Mohan, V. Decreased serum interleukin17 and increased transforming growth factor $\beta$ levels in subjects with metabolic syndrome (Chennai Urban Rural Epidemiology Study-95). Metabolism 2011, 60, 586-590. [CrossRef] [PubMed]

31. Ohshima, K.; Mogi, M.; Jing, F.; Iwanami, J.; Tsukuda, K.; Min, L.J.; Higaki, J.; Horiuchi, M. Roles of interleukin 17 in angiotensin II type 1 receptor-mediated insulin resistance. Hypertension 2012, 59, 493-499. [CrossRef] [PubMed]

32. Zúñiga, L.A.; Shen, W.J.; Joyce-Shaikh, B.; Pyatnova, E.A.; Richards, A.G.; Thom, C.; Andrade, S.M.; Cua, D.J.; Kraemer, F.B.; Butcher, E.C. IL-17 regulates adipogenesis, glucose homeostasis, and obesity. J. Immunol. 2010, 185, 6947-6959. [CrossRef] [PubMed]

33. Eid, R.E.; Rao, D.A.; Zhou, J.; Lo, S.F.; Ranjbaran, H.; Gallo, A.; Sokol, S.I.; Pfau, S.; Pober, J.S.; Tellides, G. Interleukin-17 and interferon-gamma are produced concomitantly by human coronary arteryinfiltrating $\mathrm{T}$ cells and act synergistically on vascular smooth muscle cells. Circulation 2009, 119, 1424-1432. [CrossRef] [PubMed]

34. De Boer, O.J.; van der Meer, J.J.; Teeling, P.; van der Loos, C.M.; Idu, M.M.; van Maldegem, F.; Aten, J.; van der Wal, A.C. Differential expression of interleukin-17 family cytokines in intact and complicated human atherosclerotic plaques. J. Pathol. 2010, 220, 499-508. [CrossRef] [PubMed]

35. Hashmi, S.; Zeng, Q.T. Role of interleukin-17 and interleukin-17-induced cytokines interleukin-6 and interleukin-8 in unstable coronary artery disease. Coron. Artery Dis. 2006, 17, 699-706. [CrossRef] [PubMed]

36. Nordlohne, J.; von Vietinghoff, S. Interleukin 17A in atherosclerosis-Regulation and pathophysiologic effector function. Cytokine 2017. [CrossRef] [PubMed]

37. Gong, F.; Liu, Z.; Liu, J.; Zhou, P.; Liu, Y.; Lu, X. The paradoxical role of IL-17 in atherosclerosis. Cell. Immunol. 2015, 297, 33-39. [CrossRef] [PubMed]

38. Butcher, M.J.; Waseem, T.C.; Galkina, E.V. Smooth Muscle Cell-Derived Interleukin-17C Plays an Atherogenic Role via the Recruitment of Proinflammatory Interleukin-17A + T Cells to the Aorta. Arterioscler. Thromb. Vasc. Biol. 2016, 36, 1496-1506. [CrossRef] [PubMed]

(C) 2019 by the authors. Licensee MDPI, Basel, Switzerland. This article is an open access article distributed under the terms and conditions of the Creative Commons Attribution (CC BY) license (http://creativecommons.org/licenses/by/4.0/). 